\title{
Resistência à Remoção por Tração em Restaurações Classe V com Resinas Compostas Fotopolimerizáveis e Quimicamente Ativadas
}

\author{
Alcione Scur* \\ Carlos Venturella Leite** \\ Leo Werner Suffert***
}

\begin{abstract}
RESUMO
Os autores realizaram testes de resistência à remoção por tração de restaurações classe $\mathrm{V}$ com resinas compostas fotopolimerizáveis e quimicamente ativadas.

Os resultados, segundo a metodologia empregada, mostraram diferenças significativas do DURAFILL em relação aos demais materiais testados

(MIRADAPT, ALPHA LIGHT E PRISMA FILL).
\end{abstract}

\section{SUMMARY}

The authors conducted tests verifying the resistance to removal by traction forces of class $\mathrm{V}$ restorations of composite resins, comparing photopolimerized with chemically activated resins.

the results, according to the methodology employed, showed significant differences of DURAFILL with relation to the other materials tested (MIRADAPT, ALPHA LIGHT and PRISMA FILL).

As resinas compostas vêm alcançando um lugar de destaque entre os materiais restauradores estéticos. Um número muito grande de pesquisas com este material são encontradas na literatura, contudo, tal material ainda não encontrou seu completo desenvolvimento.

Durante um certo período de tempo, todas as resinas compostas existentes no mercado eram semeIhantes quanto à sua composição química. O seu sucessivo aperfeiçoamento vem ocorrendo através de modificações no material de carga, no agente de união e no tipo de combinaçōes dos diacrilatos (3).
$\mathrm{Na}$ cavidade bucal os materiais restauradores são expostos às forças mastigatórias que causam pressões tensionais, compressivas, de clivagem e deslizamento (7).

Uma das tentativas de melhoria deste material foram as resinas compostas fotopolimerizáveis, que segundo os trabalhos como os de BLANKENAU (1), GALAN JR. (2), MAGRO e GARONE NETO (5), NEWMAN (6), VIEIRA (8), oferecem as seguintes vantagens em relação aos quimicamente ativados:

- Economia de tempo gasto na confecção da restauração, por ser mais rápida a polimerização.
- Eliminação da fase de espatulação, tendo como consequeência menor porosidade, pois diminui ou elimina a presença de bolhas de ar.

- Menor tempo de acabamento, pois existe maior controle do material utilizado.

- Melhor controle da cor. 
- Economia de material.

- Superfície mais lisa no acabamento final.

Com o intuito de contribuir para esses estudos realizamos testes comparativos de resistência à remoção de restaurações tipo classe $V$, elaboradas com resinas compostas fotopolimerizáveis e com uma resina quimicamente ativada, visando detectar eventuais diferenças entre cada uma delas.

\section{MATERIAL E MÉTODO}

Os estudos foram desenvolvidos através de testes IN VITRO, utilizando dentes humanos extraídos e previamente acondicionados em sor o fisiológico. Foram selecionados, entre caninos, laterais e centrais, dentes que possuiam boa estrutura de esmalte. Quatro marcas de resinas encontradas facilmente no comércio serviram para a confecção das restaurações. As procedências e respectivas características estão dispostas na Tabela 1.

As cavidades executadas nos dentes foram padronizadas e obedeceram às seguintes técnicas de confeç̧ão:

a) preparo inicial da cavidade utilizando ponta montada diamantada n. 557 em ultra alta velocidade, tipo Roll Air. Esta estava acoplada a uma base especialmente montada para deixar a peça de mão com um único movimento vertical (4). O dente ficou estabilizado em uma base acoplada a uma mesa de microscópio com movimentos para posicionamento do dente sob a peça de mão montada na outra base. Com o dente fixado na forma descrita e com um movimento vertical foi confeccionada a cavidade tipo classe V padronizada (4). A profundidade da cavidade foi padr onizada através de um "stop" montado na peça de mão.

b) após o preparo inicial os dentes foram levados ao microscópio estereoscópico, marca Wild, para detectar possíveis retenções que foram eliminadas com o auxílio de uma ponta montada diamantada $n$. 701 em baixa rotação.

c) o acabamento das cavidades foi feito com instrumentos manuais. Ao final as cavidades preparadas apresentaram uma forma arredondada com as paredes circundantes ligeiramente expulsivas para vestibular e a parede axial plana.

\section{TÉCNICA dE RESTAURAÇÃo}

a) profilaxia: todas as peças dentárias foram submetidas a uma profilaxia inicial, utilizando-se para tanto uma taça de borracha e branco da espanha montados em contra ângulo.

b) ataque ácido em todas as peças foi feito ataque ácido utilizandose o ácido or tofosfórico indicado pelo fabricante. Com o auxílio de uma bolinha de algodão foi aplicado pelo tempo de 60 segundos ao redor das cavidades. Decorrido esse tempo, as peças dentárias foram levadas com jatos de água por um minuto, sendo secas logo após com o auxílio de uma seringa tríplice.

c) matriz: foi confeccionada uma matriz de poliester com uma perfuração no centro, por onde passava a haste da broca que seria utilizada para fazer o esforço de remoção da restauração da cavidade. A broca utilizada para efetuar 0 esforço foi uma de haste longa n. 1 do tipo roda.

d) aplicação da resina: seguindo a orientação do fabricante foi espatulada a resina e o agente de união pelo tempo recomendado e, após, levada à cavidade. Em seguida fezse a compressão com a matriz de poliéster simultaneamente, com a introdução da broca de roda, haste longa n: 1, sendo que esta foi imobilizada com um dispositivo especialmente montado para tal.

e) término da restauração: decorrido o tempo estipulado pelo fabricante para polimerização a peça dentária era retirada do dispositivo de fixação e removida a matriz de poliéster, ficando a broca de roda fixa no interior da restauração. f) armazenagem: concluída a confecção dos ensaios foram os mesmos acondicionados por cinco dias em estufa úmida a $37^{\circ} \mathrm{C}$.

g) remoção da restauração: decorrido o prazo de cinco dias, os espécimes foram submetidos à tração através do aparelho para ensaio universal, marca LOS $250 \mathrm{KP}$, e a força de remoşão medida como mostra a Tabela 2.

Os procedimentos acima descritos foram utilizados para a confecção dos ensaios com resina quimicamente ativada, sendo que para as fotopolimerizáveis a técnica utilizada foi a seguinte:

- aplicação do agente de união: com o auxílio de um pincel foi aplicada uma camada homogênea do agente de união em todo o inferior da cavidade e na zona submetida ao ataque ácido. Em todas as peças foi imediatamente polimerizado o agente de união pelo tempo de 20 segundos. $O$ aparelho usado para a polimerização foi o TRANSLUX, da Kulzer.

- aplicação da resina: logo após a polimerização do agente de união, foi aplicada a resina e, simultaneamente, a broca de roda n. 01 que foi imobilizada no interior da cavidade através do dispositivo citado anteriormente. $O$ tempo de polimerização, por luz visível, foi o recomendado pelo fabricante.

- conclusão da restauração: após a polimerização o ensaio foi removido do dispositivo que o imobilizava, ficando a broca de roda $n$. 01 presa e centrada no interior da cavidade.

\section{RESULTADOS E DISCUSSÃO}

Com o objetivo de verificar a existência ou não de diferenças quanto à força necessária para a remoção da restauração da cavidade, os dados da Tabela 2, de acordo com o planejamento experimental, foram submetidos a tratamento estatístico por análise de variância, conforme demonstra a Tabela 3. 
Verificando os dados obtidos, o " $F$ " calculado é maior que o " $F$ " da tabela em ambos os níveis, ou seja rejeita-se a hipótese de nulidade e conclui-se que as médias obtidas são diferentes.

Os cálculos para o teste de " $t$ " aos níveis de 05 e 01 , nos mostram que as diferenças mínimas significativas são respectivamente os valores de 715 e 992 gramas.

Os dados apresentados sugerem que a resina DURAFILL proporcionou índices mais elevados (Tabela 2), possuindo diferenças significativas em relação aos demais materiais testados nestas condições experimentais (Tabela 3 e Gráfico 1).

Este resultado, talvez indique a possibilidade de que o material que tem carga inorgânica no agente de união, caso do DURAFILL, ofereça maior resistência à remoção da restauração da cavidade. Contudo, maiores estudos se fazem necessários para melhor comprovação.

Um fato que nos chamou atenção foi que, ao serem polimerizados simultaneamente $o$ agente de união e a resina, os resultados mostraram diferenças maiores do que os polimerizados em separado. Quando a polimerização era efetuada como recomendam alguns fabricantes, a força de remoção era sensivelmente menor do que quando polimerizada separadamente.

Este fato talvez possa ser explicado levando-se em conta que ao ser a resina líquida (agente de união) polimerizada primeiramente, essa polimerização se dará em maior grau no interior da cavidade e mesmo na zona atacada do esmalte ("tags").

Tendo em vista que esses fatos vêm contra a indicação de alguns fabricantes, melhores e mais aprofundados estudos devem ser feitos a esse respeito.

ANEXOS

TABELA 1

\begin{tabular}{|c|l|c|}
\hline MATERIAL & FABRICANTE & TIPO DE POLIMERIZAÇÃO \\
\hline Miradapt (a) & Johnson \& Johnson & Autopolimerizável \\
\hline Alpha Light (b) & Dental Fillings & Fotopolimerizável \\
\hline Durafill (c) & Kulzer & Fotopolimerizável \\
\hline Prisma Fill (d) & Caulk & Fotopolimerizável \\
\hline
\end{tabular}

TABELA 2

\begin{tabular}{|c|c|c|c|c|}
\hline \multicolumn{5}{|c|}{$\begin{array}{c}\text { Esforço realizado para a remoção das restaurações } \\
\text { expresso em gramas }\end{array}$} \\
\hline EI & Miradapt & Alpha Light & Durafill & Prisma Fill \\
\hline 01 & 3400 & 1700 & 7000 & 4000 \\
02 & 3000 & 3400 & 6800 & 3000 \\
03 & 3160 & 3100 & 6400 & 3400 \\
04 & 2100 & 3100 & 6800 & 4000 \\
05 & 2900 & 3600 & 5000 & 3800 \\
06 & 2600 & 3500 & 5300 & 4400 \\
07 & 2400 & 3500 & 5500 & 3700 \\
08 & & 3600 & 7800 & \\
09 & & 3100 & & \\
\hline
\end{tabular}

TABELA 3

\begin{tabular}{|l|c|c|c|c|}
\hline & Miradapt & Alpha Light & Durafill & Prisma Fill \\
\hline médias & $2786 \mathrm{~g}$ & $3178 \mathrm{~g}$ & $6325 \mathrm{~g}$ & $3757 \mathrm{~g}$ \\
\hline Desv. Padr. & 445 & 593 & 969 & 454 \\
\hline Variância & 198.095 & 351.954 & 939286 & 206.190 \\
\hline Coef. Var. & $15,97 \%$ & $18,66 \%$ & $15,32 \%$ & $12,08 \%$ \\
\hline
\end{tabular}

\section{CONCLUSÃo}

De acordo com a análise de nossos resultados e sob as condições experimentais estudadas podemos concluir que:

1. Dos materiais testados, a nível estatístico, não existem diferenças estatísticas entre as médias de MlRADAPT e ALPHA LIGHT, bem como entre ALPHA LIGHT e PRISMA FILL.

2. Existe diferença significativa ao nível de 05, entre MIRADAPT e PRISMA FILL.
3. Existem diferenças altamente significativas ao nível de 01 entre os seguintes materiais: DURAFILL e MIRADAPT; DURAFILL e ALPHA LIGHT; DURAFILL e PRISMA FILL.

A proximidade dos resultados obtidos estatisticamente entre os materiais MIRADAPT e ALPHA LIGHT, pode atribuir-se ao fato de que os agentes de união dos mesmos, apesar de terem sistemas de polimerização diferentes, quimicamente são muito semelhantes. Um trabalho clínico, neste sentido, se faz necessário para averiguar até 
que ponto essas diferenças podem influenciar o sucesso clínico da restauração.

Já os materiais MIRADAPT e PRISMA FILL que apresentam diferenças significativas, nos fazem pensar que tal fato pode ser justificado não só pelo sistema de polimerização ser diferente, como também pela composição de ambos já que a resina PRISMA FILL possui em sua composição partículas inorgânicas classificadas como finas (1 a 15 micrômetros) e que o MIRADAPT é um material de carga híbrida, mas que possui como desvantagem a possibilidade de, invariavelmente, ter a incorporação de bolhas de ar quando de sua manipulação.

Desta forma, pelos testes realizados, aconselhamos, quando da utilização de resinas compostas fotopolimerizáveis, realizar primeiramente a polimerização do agente de união. Logo após, inserir a resina polimerizando-a, pois, em todos os nossos testes, esses procedimentos apresentaram resultados superiores.

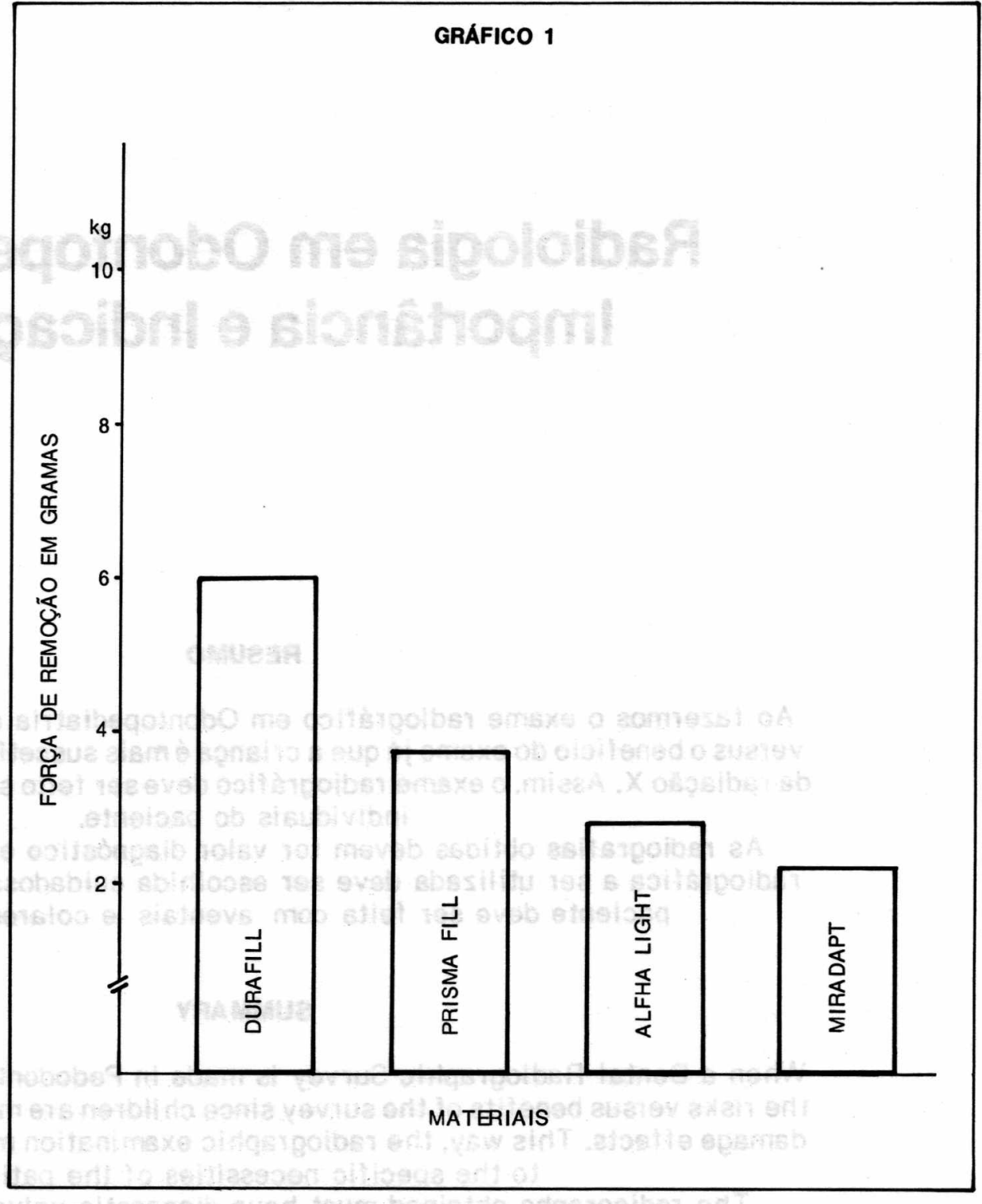

\section{REFERÊNCIAS BIBLIOGRÁFICAS}

1. BLANKENAU, Richard J. et alii. Wavelenght and intensity of seven systems for visible light-curing composite resins: a comparison study. J. Am. Dent. Assoc. 106(4):471-4, April 1986.

2. GALAN JR., João et alii. Profundidade de polimerização de resinas compostas ativadas por luz. Rev. Paul. Odont. 6(6):27-9 nov./dez. 1984.

3. GARONE NETTO, Narciso. Restauraçס̄es com resinas compostas. In: BOTTINO, Marco Antonio \& FELLER, Christina, coord. Atualização clínica em Odontologia. São Paulo, Artes Médicas, 1984. Cap. 43, p.141-62.

4. LEITE, Carlos V. Estudo comparativo da ação de alguns vernizes cavitários no bloqueio da infilt raçäo marginal de restauraçōes à amálgama submetidas a ciclagem térmica. Bauru, 1978, p. (Tese - Fac. Odont. de Bauru, USP).
5. MAGRO, Beatriz Moreira \& GARONE NETTO, Narciso. Polimerização de resinas compostas ativadas fisicamente; importância da profundidade da cavidade, tipo de retenção mecânica e tempo de exposiçăo do a tivador. Rev. Assoc. Paul. Cir. Dent., 36(2):259-64, mar./abr. 1982.

6. NEWMAN, Sheldon M. et alii. Visible lights and visible light activated composite resins. J. Prost. Dent., 5O(1):31-5, July 1983.

7. SANTOS, J.F. \& LEINFELDER, K.F. O es tágio atual das resinas compostas. Rev. Assoc. Paul. Cir. Dent., 36(3):322-35, maiol jun. 1982.

8. VIEIRA, Dioracy F. Resinas compostas depoimento exclusivo. Rev. Gaticho Odontol., 27(2):101-8, abr./jun. 1979.

9. VENZ, S. \& KOLLMANNSPERGER, P. Comparison of the physical properties of composite and polishable filling resins. Quintessence Internatl., 14(2):227-33, feb. 1983. 